\title{
Dietary exchange model to investigate the metabolic effects of extrinsic sugars on an atherogenic lipoprotein phenotype
}

\author{
C. Isherwood ${ }^{1}$, A. Ahmad ${ }^{1}$, J. A. Lovegrove ${ }^{2}$, G. S. Frost ${ }^{3}$, A. M. Umpleby ${ }^{1}$ and B. A. Griffin ${ }^{1}$ \\ ${ }^{1}$ Faculty of Health and Medical Sciences, University of Surrey, Guildford, Surrey GU2 7XH, UK, ${ }^{2}$ Department of Food and \\ Nutritional Sciences and ICMR, University of Reading, Reading RG6 6AP, UK and ${ }^{3}$ Department of Medicine, Imperial \\ College, London SW7 2AZ, UK
}

The extrinsic sugars, sucrose and fructose, have been implicated in the accumulation of liver fat, insulin resistance and formation of an atherogenic lipoprotein phenotype (ALP) ${ }^{(1)}$. A dietary-exchange model was developed as part of a metabolic tracer study to investigate the influence of these sugars on the formation of an ALP in men with low $(<5 \%)$ and moderately high $(>10 \%)$ liver fat. The model was tested in two, 12-week diets, high and low in extrinsic sugars, that were delivered in a randomised cross-over design. All male participants ( $n$ 18, aged 40-65 years), expressed increased cardio-metabolic risk ${ }^{(2)}$. The dietary model was based on NDNS data from an average intake of men aged 35-64 years ${ }^{(3)}$. It aimed to exchange two-thirds of dietary carbohydrate $(\mathrm{CHO})$ in six portions of food, containing approximately $30 \mathrm{~g}$ CHO per portion. Supermarket foods, with either a high $(>40 \%)$ or low $(<10 \%)$ sugar content, were selected to achieve target ratios of starch to sugar of $1: 1.2$ and 5:1, respectively. The diets were designed to be matched for total energy, CHO, fat, protein and fibre content. Participants received weekly home visits for the delivery of foods and dietary counselling. Dietary intakes were measured by 3-d food diaries and 'DietPlan6' (version 6.5).

The test diets achieved significant changes in the relative proportion of sugars via the exchange of staple foods (bread), snacks (crisps, biscuits, cakes), cereals (Frosties, cornflakes) and drinks (high sugar only), and were well tolerated by the participants.

\begin{tabular}{|c|c|c|c|c|c|}
\hline \multirow[b]{2}{*}{ Nutrient } & \multirow{2}{*}{$\begin{array}{c}\text { Habitual } \\
\text { Diet }\end{array}$} & \multicolumn{2}{|c|}{ High Sugar } & \multicolumn{2}{|c|}{ Low Sugar } \\
\hline & & Achieved & Target & Achieved & Target \\
\hline Total energy $(\mathrm{E})(\mathrm{MJ})$ & $9.8(0.6)$ & $10.6(0.6)$ & - & $10.0(0.4)$ & - \\
\hline$\% \mathrm{E} \mathrm{CHO}$ & $42(1.0)$ & $50(1.5)^{\mathrm{b}}$ & 44 & $39(1.1)^{\mathrm{a}}$ & 44 \\
\hline$\%$ E Sugar & $19(1.0)$ & $27(1.3)^{\mathrm{b}}$ & 24 & $9(0.5)^{\mathrm{ab}}$ & 6 \\
\hline$\%$ E Fat & $34(1.0)$ & $27(1.9)^{\mathrm{b}}$ & 33 & $35(1.3)^{\mathrm{a}}$ & 33 \\
\hline$\%$ E Protein & $16(0.7)$ & $14(0.5)$ & 15 & $17(0.7)^{\mathrm{a}}$ & 15 \\
\hline Fibre $(\mathrm{g})$ & $26(1.8)$ & $21(1.4)^{b}$ & 16 & $24(1.9)$ & 16 \\
\hline Starch:sugar ratio & 1:08 & $1: 12$ & $1: 1.2$ & 3:1 & $5: 1$ \\
\hline
\end{tabular}

Values are means (SEM) ${ }^{\mathrm{a}} \mathrm{P}<0.01$ (High vs Low Sugar); ${ }^{\mathrm{b}} \mathrm{P}<0.01$ (Habitual vs High or Low Sugar).

The high sugar diet met the target ratio of starch to sugar, but exceeded the predicted energy contribution from sugar and CHO. The low sugar diet fell short of the target starch to sugar ratio, but still produced a three-fold increase in starch relative to sugar, and reduced the energy from sugar by $63 \%$ relative to the habitual diet. There was no difference in total energy intake between any of the diets, but the energy contribution from fat and protein was significantly reduced on the high-sugar diet. There was no difference in dietary fibre (AOAC) between the high- and low-sugar diets. In conclusion, the dietary exchange model was successful in achieving an intake of sugar diet that was close to the upper 2.5 percentile $(28 \% \mathrm{E})$ for the intake of non-milk extrinsic sugars in the UK (lower 2.5 percentile $3 \% \mathrm{E})^{(3)}$. It should provide an effective tool for studying the metabolic impact of extrinsic sugars on an ALP.

This work was funded by the BBSRC (Grant no. BB/G009899/1).

1. Stanhope KL \& Havel PJ (2008) Curr Opin Lipidol 19, 16-24.

2. Jebb SA, Lovegrove JA, Griffin BA et al. (2010) Am J Clin Nutr 92, 748-758

3. National Diet and Nutrition Survey: adults aged 19-64 years, vol 2 (2003) HMSO. 